\title{
Biological Control of Fusarium Crown and Root Rot of Wheat by Streptomyces Isolates - It's Complicated
}

\author{
Mark Winter, ${ }^{1, \dagger}$ Peter L. Samuels, ${ }^{2}$ Lindsey K. Otto-Hanson, ${ }^{2}$ Ruth Dill-Macky, ${ }^{2}$ and Linda L. Kinkel ${ }^{2}$ \\ ${ }^{1}$ Department of Crop Sciences, Göttingen University, 37077 Göttingen, Germany; and ${ }^{2}$ Department of Plant \\ Pathology, University of Minnesota, St. Paul, MN 55108
}

Accepted for publication 24 January 2019.

\section{ABSTRACT}

The predominant causal agents of Fusarium crown and root rot (FCR) of wheat, along with Fusarium pseudograminearum, are $F$. graminearum and F. culmorum. Members of the Gram-positive bacterial genus Streptomyces have been shown to inhibit isolates of the genus Fusarium, and Fusarium spp. isolates are also able to inhibit Streptomyces isolates in vitro. However, little is known about these complex antagonistic interactions and the potential for inhibitory Streptomyces to reduce FCR of wheat. The aim of this study was to analyze whether inhibitory Streptomyces isolates affect FCR of wheat and reduce root and stem base colonization by Fusarium culmorum. We enriched sterilized potting soil with spore suspensions of two Streptomyces isolates, inoculated the soil with F. culmorum-colonized wheat straw, and planted pre-germinated wheat seedlings. At 4 weeks, F. culmorum-inoculated plants had significant FCR symptoms on roots and showed reduced fresh weight of roots and above-ground plant biomass compared with the non-inoculated controls. Enrichment of soil with an inhibitory Streptomyces isolate reduced $F$. culmorum DNA in roots and stem bases by $75 \%$ compared with inoculation with $F$. culmorum alone. Interestingly, co-inoculation of $F$. culmorum with a non-inhibitory
Streptomyces isolate led to the highest levels F. culmorum DNA in stem base tissue and greatest Streptomyces densities (CFU per g of soil) in the rhizosphere. In vitro assays revealed that F. culmorum showed a strong inhibitory activity against the pathogen-inhibitory Streptomyces isolate but not against the noninhibitory isolate. In vitro tests with a larger set of 17 Streptomyces and five Fusarium spp. isolates revealed that there was little variation among Fusarium spp. isolates in capacities to inhibit the collection of Streptomyces isolates. In contrast, the sensitivity to inhibition by pathogenic Fusarium spp. isolates varied widely among Streptomyces isolates. The results of this study suggest the potential of Streptomyces isolates for biocontrol of FCR of wheat, while highlighting the specificity of Streptomyces-Fusarium interactions. Broader understanding of the variation in susceptibility within Fusarium spp. populations to Streptomyces inhibition and vice versa are needed to advance the potential for successful biological control.

Keywords: antagonism, Fusarium culmorum, Fusarium foot and root rot, Fusarium graminearum.
Fusarium crown and root rot (FCR) of wheat is a soilborne disease that occurs in most wheat-growing areas worldwide (Moya-Elizondo 2013). Significant yield losses attributed to FCR are reported from dryland wheat-growing regions including the Pacific Northwest of the United States, Australia, and the Middle East (Fouly and Pedersen

${ }^{\dagger}$ Corresponding author: M. Winter; mark.winter@agr.uni-goettingen.de

Funding: Funding was provided by a postdoctoral fellowship for M. Winter from the German Research Foundation (Deutsche Forschungsgemeinschaft).

*The $e$-Xtra logo stands for "electronic extra" and indicates that two supplementary tables are published online.

The author(s) declare no conflict of interest.

(C) 2019 The American Phytopathological Society
1996; Poole et al. 2013; Wildermuth et al. 1997). With global climate change predicted to increase the frequencies and intensities of droughts, and changes in rainfall patterns across many wheat production regions, the prevalence of FCR is expected to increase in areas where it is currently reported and expand into other wheat production areas (Moya-Elizondo 2013). The predominant causal agents of FCR are, along with Fusarium pseudograminearum O'Donnell and Aoki, the ascomycetous fungi F. culmorum (W.G. Smith) Sacc., and F. graminearum Schwabe (Burgess et al. 1993; Chekali et al. 2011; Paulitz et al. 2002; Smiley and Patterson 1996). The primary sources of inoculum for FCR infections are soilborne chlamydospores and infested plant debris in the upper $(\sim 10 \mathrm{~cm})$ soil surface layer (Cook 1980). Stem base and root infections of wheat by $F$. culmorum and $F$. graminearum can take place as early as the seedling stage and may result in seedling blight (Scherm et al. 2013). Early infection is initiated by germinating mycelium invading the 
rhizodermal root tissue and infecting the coleoptile (Beccari et al. 2011; Duthie and Hall 1987). In later stages, the pathogen colonizes the whole stem base up to the third node (Beccari et al. 2011; Clement and Parry 1998; Cook 1981). Infection of the crown of the plant results in impaired vascular tissue function and increases lodging, and both symptoms contribute to yield losses (Clement and Parry 1998; Smiley and Patterson 1996). In addition to their pathogenic lifestyle, Fusarium species are considered to be ubiquitous saprophytes, and can play important roles in nutrient cycling and are strongly interacting with the soil microbial community (King et al. 2011; LeBlanc et al. 2017; Li et al. 2008).

The genus Streptomyces consists of several hundred species of Gram-positive filamentous bacteria in the phylum Actinobacteria. Streptomyces are omnipresent in soil and the plant rhizosphere and are recognized for their significant ability to produce highly diverse antibiotics in remarkable quantities (Challis and Hopwood 2003; Watve et al. 2001). In diverse crop production systems, Streptomyces have been shown to suppress soilborne diseases caused by plant pathogenic fungi, bacteria, and nematodes (Samac and Kinkel 2001; Wiggins and Kinkel 2005a, 2005b). This suppression is achieved through multiple mechanisms, including antibiosis and competition for nutrients and space, induced resistance in the host plant, quorum quenching, degradative enzymes, and the production of nitrous oxide (Cohen and Mazzola 2006; Cohen et al. 2005; Mahadevan and Crawford 1997; Mahmoudi et al. 2011).

Although Streptomyces, F. culmorum, and $F$. graminearum are members of the microbial community in many agricultural soils, information on their interactions, including reciprocal antagonistic inhibitory activity, is scarce. A recent study showed that members of the genus Streptomyces possessed strong inhibitory activity against various coexisting Fusarium species, and Fusarium spp. isolates were also able to inhibit Streptomyces isolates in vitro (Essarioui et al. 2017). The authors found that the occurrence of strong Fusarium-antagonistic Streptomyces and Streptomyces-antagonistic Fusarium phenotypes is influenced by the richness of the plant community and resource competition, and showed that Fusarium spp. and Streptomyces isolates develop a competitive and/or antagonistic relationship in soil. However, little is known about these complex interactions in agricultural settings, including the potential for inhibitory Streptomyces isolates to reduce FCR of wheat. In this study we analyzed the effects of Streptomyces isolates on FCR of wheat and specifically whether Streptomyces can reduce root and stem base colonization by $F$. culmorum, as measured by the levels of $F$. culmorum DNA in these tissues. Further, we analyzed Streptomyces and Fusarium spp. isolate inhibitory interactions and whether reciprocal interactions play a role in biocontrol. The specific objectives of this work were (i) to characterize the inhibitory interactions and resource competition between Streptomyces isolates and isolates of $F$. culmorum and $F$. graminearum, and (ii) to analyze whether the enrichment of soil with a Fusariumantagonistic Streptomyces isolate can effectively reduce soilborne colonization of wheat roots and stem bases by F. culmorum. Together, we wanted to evaluate whether in vitro inhibitory interactions and resource competition between Streptomyces and Fusarium spp. isolates can explain biological control of FCR of wheat by Streptomyces under controlled conditions. This research highlights the complex isolate-specific interactions between Streptomyces and Fusarium spp. isolates and the potential to control a prevalent disease using pathogen suppressive Streptomyces.

\section{MATERIALS AND METHODS}

Fusarium isolates. Pathogenic F. culmorum isolates 10212001, 10286002,10281010 , and the $F$. graminearum isolate 10100004 selected from the collection of the Small Grains Pathology Laboratory, Department of Plant Pathology at the University of Minnesota, U.S.A., and F. graminearum isolate 02-15 from the fungal collection of the USDA-ARS Cereal Disease Laboratory, St. Paul, MN, U.S.A., were used in this work. Isolates were selected based on their capacity to cause varying levels of FCR in wheat in growth chamber experiments (Winter et al. 2018).

Streptomyces isolates. To study the interaction between the five pathogenic Fusarium spp. isolates and Streptomyces during FCR of wheat, nine Streptomyces isolates were obtained from wheat rhizospheres collected from four non-tilled fields (two isolates per field for three fields and three for one field) after harvest in October 2015. Briefly, stubble of wheat plants, including roots and attached soil (three to five stubbles per field) were collected in the Red River valley in northwest Minnesota. Rhizosphere soil samples were obtained within $24 \mathrm{~h}$ after sampling by shaking the attached soil from wheat roots, air-drying soil overnight under two layers of sterile cheesecloth, and storing soil in sealed plastic bags in the refrigerator prior to processing. For Streptomyces isolation, $5 \mathrm{~g}$ of soil was suspended in $50 \mathrm{ml}$ of sterile distilled water in a $125 \mathrm{ml}$ Erlenmeyer flask and shaken for $1 \mathrm{~h}$ on a reciprocal shaker $\left(175 \mathrm{rpm}, 4^{\circ} \mathrm{C}\right)$. After sedimentation for $10 \mathrm{~min}$, the supernatant was serially diluted to 1:100 and 1:1,000, and $100 \mu \mathrm{l}$ was spread using a Drigalski spatula onto the surface of $1 \%$ water agar (WA) medium in Petri plates. Plates were incubated at $28^{\circ} \mathrm{C}$ for 3 days. Colonies with typical Streptomyces appearance, Streptomyces exhibit characteristic powdery sporulation on WA medium, and the vast majority of isolates with this morphology are in the genus Streptomyces (more than $95 \%$ based on own $16 \mathrm{~S}$ sequence analysis, data not shown), were transferred to Petri plates containing oatmeal agar (OA) (Lorang et al. 1995). Plates were incubated at $28^{\circ} \mathrm{C}$ for 10 days, and isolates were harvested with sterile cotton swabs into $20 \%$ glycerol at $1.0 \times 10^{8}$ colony forming units (CFU) per $\mathrm{ml}$ and stored in $2 \mathrm{ml}$ aliquots at $-20^{\circ} \mathrm{C}$. Additionally, eight Streptomyces isolates, 3211.1, 1231.5, 3212.5, 2233.5, 2311.3, GS4-24, GS4-17, and GS8-22, with known inhibitory potential toward Fusarium spp. isolates (L. Kinkel, University of Minnesota, St. Paul, MN) were used in the inhibitory assays (Supplementary Table S2). This set includes isolates from both native prairie soils and agricultural fields.

Inhibitory potential of Streptomyces isolates against isolates of the species $\boldsymbol{F}$. culmorum and $\boldsymbol{F}$. graminearum. The inhibitory potential of Streptomyces isolates against Fusarium spp. isolates (all possible pairwise combinations) was tested in an in vitro assay on OA medium as previously described (Essarioui et al. 2017). Briefly, Petri plates containing OA were inoculated in the center with a plug (7 mm diameter) cut from within a Fusarium spp. colony grown on potato dextrose agar medium (PDA). Three Streptomyces colonies were dotted onto the plate $(4 \mu \mathrm{l}$ at a density of $1.0 \times 10^{8} \mathrm{CFU}$ per $\mathrm{ml}$ ) at equal distances from each other and $2.75 \mathrm{~cm}$ from the Fusarium agar center plug, and the plates were incubated at $28^{\circ} \mathrm{C}$ for 5 to 7 days, or until mycelial growth reached the edge of the plate. Inhibition of each Streptomyces isolate against a Fusarium spp. isolate was quantified as the average distance ( $\mathrm{mm}$ ) between the outer edge of the Streptomyces colony for an isolate and the outer edge of the cleared inhibition zone surrounding the colony, as measured in two directions at right angles to each other. Each Streptomyces-Fusarium combination was replicated three times, whereby the three dotted Streptomyces colonies were arbitrarily assigned to different plates. Streptomyces isolates were considered as inhibitors when the mean inhibition zone was $\geq 2 \mathrm{~mm}$ and non-inhibitors when the mean inhibition zone was $<2 \mathrm{~mm}$.

Inhibitory potential of $F$. culmorum and $F$. graminearum isolates against Streptomyces isolates. Fusarium inhibition of Streptomyces was evaluated in vitro in a manner similar to that 
described in Essarioui et al. (2017). Briefly, starch casein agar medium (SCA; $10 \mathrm{~g}$ of starch, $0.3 \mathrm{~g}$ of casein, $0.02 \mathrm{~g}$ of $\mathrm{CaCO}_{3}$, $2.0 \mathrm{~g}$ of $\mathrm{KNO}_{3}, 2.0 \mathrm{~g}$ of $\mathrm{NaCl}, 2.0 \mathrm{~g}$ of $\mathrm{K}_{2} \mathrm{HPO}_{4}, 0.05 \mathrm{~g}$ of $\mathrm{MgSO}_{4} \cdot 7 \mathrm{H}_{2} \mathrm{O}, 0.01 \mathrm{~g}$ of $\mathrm{FeSO}_{4} \cdot 7 \mathrm{H}_{2} \mathrm{O}, 0.001 \mathrm{~g}$ of $\mathrm{ZnCl}_{2}$, and $15 \mathrm{~g}$ of agar per liter of deionized $\mathrm{H}_{2} \mathrm{O}$ ) was first inoculated by spreading a spore suspension of a Streptomyces isolate over the entire surface of the SCA medium $\left(100 \mu \mathrm{l}\right.$ at $1.0 \times 10^{6} \mathrm{CFU}$ per ml per plate) (Becker and Kinkel 1999). For each Fusarium spp. isolate, three agar plugs (PDA, $7 \mathrm{~mm}$ diameter), taken from the growing edge of a 7- to 10-day-old culture were placed $2.75 \mathrm{~cm}$ from the center of the plate, and placed equidistant with respect to each other. Plates were inverted and incubated overnight at 4 to $5^{\circ} \mathrm{C}$ in order to allow antimicrobial compounds produced by Fusarium to diffuse into the medium. Plates were subsequently incubated at $28^{\circ} \mathrm{C}$ for 3 to 4 days. Inhibition zones were measured as described above.

Streptomyces and Fusarium resource use characterization. Resource use profiles were evaluated for Fusarium spp. isolates $(n=5)$ and Streptomyces $(n=9)$ isolates obtained from the field soil samples using Biolog SF-P2 microplates (Biolog, Inc., Hayward, CA) as described previously with a slight modification (Essarioui et al. 2017; Schlatter et al. 2009). Briefly, Fusarium inoculum (macroconidia) was produced on mung bean agar (Dill-Macky 2003). Macroconidia were swabbed using a sterile cotton swab into $0.2 \%$ carrageenan and adjusted to a concentration of $1.0 \times 10^{5}$ conidia per $\mathrm{ml}$ for inoculation of Biolog microplates. Plates were incubated for 3 days at $28^{\circ} \mathrm{C}$, after which optical density (OD) was measured at $590 \mathrm{~nm}$ using a Synergy H1 Reader (BioTek Instruments, Winooski, VT). The OD for the water control was subtracted from the OD indicating growth on each of the 95 substrates tested, the resulting wells with an adjusted OD $\leq 0.005$ were considered to have an OD value of 0 . All remaining wells with non-zero OD readings were considered nutrients used for growth. In order to assess overall growth phenotypes for each isolate, total growth, average growth, and niche width were assessed. Total growth was calculated as the sum of ODs across used nutrients for each isolate. Average growth was quantified as the average OD across the number of used nutrients for a given isolate. Finally, niche width for each isolate was defined as the number of nutrients used out of the 95 possible nutrients included in the SF-P2 Biolog plates. In order to interrogate resource competition between isolates, escape from competition and effective competition were evaluated for all pairwise asymmetrical Fusarium-Streptomyces combinations, to account for the potential impact of one isolate on another, and vice versa. Escape was defined as the proportion of total growth of one isolate (Isolate A) for which there is no apparent resource competition with another isolate (Isolate $\mathrm{B}$ ):

$$
\begin{aligned}
& \text { Escape }_{\mathrm{A} \text { with respect to B }}= \\
& \left(\frac{\text { When }\left(\text { Growth }_{\mathrm{A}}-\text { Growth }_{\mathrm{B}}\right) \geq 0, \sum \text { Growth }_{\mathrm{A}}-\text { Growth }_{\mathrm{B}}}{\sum \text { Growth }_{\mathrm{A}} \text { across all nutrients }}\right) \times 100
\end{aligned}
$$

Effective competition was defined as the proportion of an isolate's total growth for which an isolate will compete directly with another isolate:

$$
\text { Effective Competition }_{\mathrm{A} \text { with respect to } \mathrm{B}}=100-\text { Escape }_{\mathrm{A} \text { with respect to } \mathrm{B}}
$$

Growth chamber experiments. For growth chamber experiments, a highly aggressive isolate of $F$. culmorum (in terms of wheat stem base infection; 10212001) and two Streptomyces isolates showing high (S05) and low (S06) inhibition of Fusarium spp. isolates in in vitro assays were used. Streptomyces isolate stocks were produced by inoculating OA media in Petri plates with $100 \mathrm{ml}$ of Streptomyces stock suspension, as described previously, and incubating them for 14 days at $28^{\circ} \mathrm{C}$. Colonies were transferred with a sterile cotton swab into $20 \%$ glycerol. The concentration of CFUs was determined by serial dilution on WA $(1 \%)$. Spore suspensions of the respective Streptomyces isolates were added to soil (3:1 ratio of potting soil to sand) at $8.0 \times 10^{5} \mathrm{CFU}$ per $\mathrm{g}$ of soil. Soil was incubated in plastic tubs $(40 \mathrm{~cm} \times 25 \mathrm{~cm} \times 14 \mathrm{~cm})$ for $24 \mathrm{~h}$ at $28^{\circ} \mathrm{C}$. Subsequently, the Streptomyces-enriched soil was inoculated with the fungal pathogen, F. culmorum, by incorporating wheat straw colonized with $F$. culmorum isolate 10212001 into soil (7.2 g of straw per $1 \mathrm{~kg}$ of soil). Fusarium-colonized wheat straw was produced as follows: $30 \mathrm{~g}$ of ground wheat straw (1 to $2 \mathrm{~cm}$ long pieces) and $20 \mathrm{ml}$ of water were autoclaved $\left(121^{\circ} \mathrm{C}\right.$ for $\left.30 \mathrm{~min}\right)$ on two consecutive days in plastic boxes $(10.5 \mathrm{~cm} \times 10.5 \mathrm{~cm} \times 9.5 \mathrm{~cm})$. Subsequently, the wheat straw was inoculated with $10 \mathrm{ml}$ spore suspension $\left(2.5 \times 10^{5}\right.$ spores per $\left.\mathrm{ml}\right)$ of $F$. culmorum per box and incubated at $21^{\circ} \mathrm{C}$ for 4 weeks. Spore suspensions of $F$. culmorum used to inoculate the straw were produced as previously described by Winter et al. (2013). Additionally, potting soil was inoculated with F. culmorum or isolate S05 or S06 of Streptomyces alone. A non-inoculated treatment served as a control, resulting in six different treatments.

The hard red spring wheat variety 'Samson' (WestBred, Monsanto, St. Louis, MO, released in 2007) was used for growth chamber experiments. Seeds were surface sterilized under constant agitation in $70 \% \mathrm{EtOH}$ for $30 \mathrm{~s}$ and subsequently washed twice in sterile deionized water. Subsequently, the surface disinfested seeds were placed on autoclaved $\left(15 \mathrm{~min}\right.$ at $\left.121^{\circ} \mathrm{C}\right)$ moist gravel $(100 \mathrm{~g})$ in glass Petri dishes and covered with aluminum foil for germination at $21^{\circ} \mathrm{C}$ for 4 days prior to planting. Pre-germinated wheat seedlings, two seedlings per pot $(20.5 \mathrm{~cm}$ [depth] $\times 4 \mathrm{~cm}$ [diameter], Deepot D33L, Stuewe \& Sons, Inc, OR), were then planted into the differentially treated potting soils. Each treatment consisted of 30 plants (15 pots).

Plants were grown in a growth chamber (Conviron, Winnipeg, Canada) under a $16: 8 \mathrm{~h}$ day/night cycle at $21 / 16^{\circ} \mathrm{C}$. After 2 weeks the number of surviving plants in each treatment was assessed as the survival rate (\%). Four weeks after planting, 24 plants per treatment were harvested. Plants were cut off just above the crown roots, fresh weight of above-ground plant material was determined and disease symptoms of FCR was visually assessed. For symptoms, disease severity on culms was rated using a 0 to 3 scale, where $0=$ no lesion visible, $1=$ lesion covering up 50\% of stem surface area, $2=$ lesion covering 51 to $100 \%$ of stem surface area, and $3=$ stem base rotten. Leaf sheaths were removed and the bottom $5 \mathrm{~cm}$ of the stem base was excised, plant tissues from the same cone were combined to one sample, flash-frozen in liquid nitrogen, and stored at $-20^{\circ} \mathrm{C}$ until used for the quantification of $F$. culmorum DNA by qPCR. Roots were gently removed from pots, loosely attached potting soil was removed by hand, and rhizosphere soil samples were obtained by shaking off the tightly attached soil from roots. Rhizosphere soil samples were used to determine the Streptomyces density in the soil by completing a serial dilution plating of a soil suspension as described above. Roots were subsequently rinsed under a faucet fitted with a spray nozzle to remove any remaining soil. After patting dry with paper towels, disease symptoms and root fresh weight were assessed.

Disease severity on roots was visually rated as the percentage of diseased root tissue. Briefly, brownish discolored root tissue was considered as diseased and assessed in relation to the healthy (not discolored) root tissue. Subsequently, roots were flash-frozen in liquid nitrogen and stored in $-20^{\circ} \mathrm{C}$ until quantification of $F$. culmorum DNA by qPCR. Both genomic DNA extraction and quantification of fungal DNA of $F$. culmorum in stem base and root tissue was conducted as described in Winter et al. (2018). 
Data analyses. Statistical analyses were performed with the computer software Statistica (StatSoft, Tulsa, U.S.A.). Data of disease severity rating at the stem base were ordinally scaled and thus the univariate non-parametric Kruskal-Wallis test was used to evaluate differences in stem base symptoms. Disease rating data from roots, fungal biomass quantifications, and Streptomyces densities were $\log$-transformed with the formula $\log (x+1)$ prior to analysis of variance (ANOVA) to obtain a suitable distribution of the residuals. Log-transformed data and the plant fresh weights were analyzed for significant differences with Tukey's posthoc test $(P \leq 0.05)$. A generalized linear model (GLM) and honestly significant difference (HSD) posthoc test $(P \leq 0.05)$ for unequal sample sizes were carried out to evaluate differences in effective competition between Fusarium spp. isolates against Streptomyces isolates S05 and S06, and vice versa, and in resource use (total growth, average growth, mean niche width) between Fusarium spp. isolates and Streptomyces isolates S05 and S06. A GLM and an HSD posthoc test $(P \leq 0.05)$ for unequal sample sizes were carried out to evaluate differences between Streptomyces densities in rhizosphere soil after subtracting background Streptomyces densities measured in the treatment inoculated with 10212001 alone, considered as a naturally occurring Streptomyces population, from measured Streptomyces densities in all treatments. Tukey's posthoc test $(P \leq$ 0.05 ) was performed using a GLM to analyze differences in inhibition between Fusarium versus Streptomyces and vice versa. The coefficient of variation (CV, \%) of Fusarium inhibition against single and all Streptomyces isolates tested was calculated as the ratio of the standard deviation to the mean.

\section{RESULTS}

Inhibitory potential of Streptomyces isolates from wheat rhizospheres. Out of the nine Streptomyces isolates tested, two (S02 and S07) exhibited no inhibition of any Fusarium spp. isolate, and five isolates showed only limited inhibition (inhibition zones $\leq 2 \mathrm{~mm}$ ) of individual Fusarium spp. isolates (Table 1). Thus, in general, resistance of Fusarium spp. isolates to inhibition by individual Streptomyces isolates was very high. However, one Streptomyces isolate (S05) inhibited the growth of all Fusarium spp. isolates with inhibition zones $\geq 3 \mathrm{~mm}$ (Table 1).
Inhibitory potential of Fusarium spp. isolates against Streptomyces isolates. We tested the inhibitory potential of $F$. culmorum $(n=3)$ and $F$. graminearum $(n=2)$ isolates against 17 Streptomyces isolates. There was little variation among Fusarium spp. isolates in their capacities to inhibit Streptomyces isolates (mean inhibition zones ranged from 2.4 to $3.5 \mathrm{~mm}$ ) (Table 2). Nevertheless, there were significant species effects (one-way ANOVA, $P=0.027): F$. graminearum displayed greater mean inhibition to Streptomyces isolates than $F$. culmorum. The mean CV (\%) of inhibition zones (Fusarium spp. against Streptomyces isolates) among Fusarium spp. isolates was $102 \%$, and varied from 82 to $118 \%$ for individual isolates. There was considerable variation in sensitivity of different Streptomyces isolates to individual Fusarium spp. isolates. Fusarium spp. isolates demonstrated low inhibition ( $<2 \mathrm{~mm}$ zone) against six Streptomyces isolates (35\%), whereas inhibition was considerable ( $\geq 2 \mathrm{~mm}$ zone) against the majority of tested Streptomyces isolates (11 isolates [65\%]).

Conversely, sensitivity to inhibition by Fusarium spp. isolates varied widely among Streptomyces isolates (mean inhibition zones ranged from 0 to $10.7 \mathrm{~mm}$ ) (Table 2). The mean $\mathrm{CV}$ of inhibition zones for individual Streptomyces isolates inhibited by Fusarium spp. isolates was $47 \%$ and varied from 0 to $131 \%$. The highest variation in sensitivity was found among the isolates from wheat fields. Isolates S03 and S09 were not inhibited in growth by any of the tested Fusarium spp. isolates, whereas S10 and S02 were highly sensitive to Fusarium spp. isolates (Table 2). Isolate $\mathrm{S} 02$ showed by far the highest sensitivity, especially to $F$. graminearum isolate 10100004, with a mean inhibition zone of $16.2 \mathrm{~mm}$ (Table 2).

Inhibitory activity of $F$. culmorum isolate 10212001 against Streptomyces isolates S05 and S06, and vice versa. F. culmorum isolate 10212001 exhibited strong inhibitory activity against Streptomyces isolate S05 but not against isolate S06 (Fig. 1). Conversely, Streptomyces isolate S05 inhibited the growth of F. culmorum isolate10212001 in vitro, but Streptomyces isolate S06 did not inhibit this isolate. The two Streptomyces isolates displayed significant differences in both inhibition against 10212001 and resistance to inhibition by 10212001 (Fig. 1). Likewise, the F. culmorum isolate inhibited the Streptomyces isolate with strong inhibitory potential against Fusarium spp. isolates, but not the noninhibitory Streptomyces isolate (Table 1, Fig. 1).

TABLE 1

Mean inhibition zones of nine Streptomyces isolates against five Fusarium spp. isolates in in vitro assays ${ }^{\mathbf{Z}}$

\begin{tabular}{|c|c|c|c|c|c|c|c|c|c|}
\hline \multirow{3}{*}{$\begin{array}{l}\text { Fusarium } \\
\text { isolates }\end{array}$} & \multicolumn{9}{|c|}{ Inhibitory potential of Streptomyces against Fusarium (mean inhibition zone $[\mathrm{mm}] \pm$ standard deviation) } \\
\hline & \multicolumn{9}{|c|}{ Streptomyces isolates } \\
\hline & S02 & S03 & S04 & S05 & S06 & S07 & S08 & S09 & S10 \\
\hline 10286002 & $0.0 \pm 0.0$ & $0.0 \pm 0.0$ & $0.0 \pm 0.0$ & $3.5 \pm 1.5$ & $0.0 \pm 0.0$ & $0.0 \pm 0.0$ & $1.2 \pm 0.3$ & $1.0 \pm 0.0$ & $0.0 \pm 0.0$ \\
\hline 10281010 & $0.0 \pm 0.0$ & $0.0 \pm 0.0$ & $1.5 \pm 0.5$ & $4.3 \pm 0.6$ & $3.5 \pm 0.9$ & $0.0 \pm 0.0$ & $2.0 \pm 0.0$ & $1.0 \pm 0.0$ & $1.0 \pm 0.0$ \\
\hline $02-15$ & $0.0 \pm 0.0$ & $0.0 \pm 0.0$ & $0.0 \pm 0.0$ & $3.3 \pm 1.5$ & $0.5 \pm 0.0$ & $0.0 \pm 0.0$ & $0.0 \pm 0.0$ & $2.0 \pm 0.0$ & $0.0 \pm 0.0$ \\
\hline Mean & $0.0 c \pm 0.0$ & $0.2 b c \pm 0.5$ & $0.3 b c \pm 0.6$ & $3.7 \mathrm{a} \pm 1.1$ & $0.9 b \pm 1.5$ & $0.0 c \pm 0.0$ & $0.8 b c \pm 0.9$ & $1.0 b \pm 0.7$ & $0.4 b c \pm 0.5$ \\
\hline \multicolumn{10}{|c|}{$\begin{array}{l}\text { z Petri plates }(9 \mathrm{~cm} \text { diameter) containing oatmeal agar }(\mathrm{OA}) \text { were inoculated in the center with an agar plug cut out from a } 5 \text {-day-old Fusarium spp. } \\
\text { colony. Three Streptomyces spp. colonies were dotted, } 4 \mu \mathrm{l} \text { at a density of } 1.0 \times 10^{8} \mathrm{CFU} \text { per ml, at equal distances from the Fusarium spp. } \\
\text { overgrown agar plug and incubated until the Fusarium colony reached the plate edge. The average inhibition of Streptomyces against Fusarium spp. } \\
\text { was measured as the distance }(\mathrm{mm}) \text { between the edge of the Streptomyces isolate and the outer edge of the cleared inhibition zone, as measured in } \\
\text { two directions at right angles to each other. Each Streptomyces-Fusarium combination was replicated three times. Streptomyces isolates were } \\
\text { considered as inhibitors when the mean inhibition zone was } \geq 2 \mathrm{~mm} \text { and as noninhibitors when the mean inhibition zone was }<2 \mathrm{~mm} \text {. Different } \\
\text { letters indicate significant differences between the mean inhibitory potential of Streptomyces isolates against Fusarium spp. according to Tukey } \\
\text { test }(P \leq 0.05) \text { performed within a generalized linear model. }\end{array}$} \\
\hline
\end{tabular}


Resource use profiles and effective competition of Fusarium spp. isolates against S05 and S06 and vice versa. Fusarium spp., inhibitory, and non-inhibitory Streptomyces isolates did not differ in niche width, average growth, or total growth (Supplementary Table S1).

Overall, there was no significant difference in the effective competitive impact of Fusarium on Streptomyces versus Streptomyces on Fusarium (one-way ANOVA, $P=0.951$ within a GLM). Effective competition was highest for Fusarium spp. isolates against Streptomyces isolate S05, which was 33\% higher than for Fusarium spp. isolates against isolate S06 (Fig. 2). In contrast, there was no difference between S05 and S06 with respect to either isolates effective competition against the tested Fusarium spp. isolates.

Growth chamber experiments. Inoculation with $F$. culmorum (isolate 10212001) led to significant colonization of wheat plants, resulting in $16 \%$ mortality (Table 3 ). When $F$. culmorum isolate 10212001 was inoculated together with either the non-inhibitory (S06) or inhibitory (S05) Streptomyces isolate, the mortality rate was higher than in the absence of Streptomyces (23\% for $10212001+\mathrm{S} 05$ and $26 \%$ for $10212001+$ S06, Table 3 ). The highest disease ratings on roots and stem bases were observed when $F$. culmorum 10212001 was co-inoculated with Streptomyces S06. Wheat root biomass was reduced after inoculation with isolate 10212001, though differences were significant only in contrast to inoculation with Streptomyces isolate S06 alone (Table 3). Above-ground plant material was significantly reduced in the $F$. culmorum-inoculated plants compared with the control and the treatments inoculated with either Streptomyces isolates (S05 and S06) alone (Table 3).

Despite greater mortality rates, co-inoculation of $F$. culmorum and Streptomyces isolates did not affect root or above-ground plant biomass of the surviving plants. DNA quantifications in root and stem base tissue showed that inoculation with F. culmorum (10212001) led to significant fungal colonization of plant tissue. Co-inoculation of F. culmorum with Streptomyces isolate S05 significantly reduced the colonization of root and stem base tissue by $F$. culmorum. In contrast, when Streptomyces isolate S06 was inoculated together with $F$. culmorum, pathogen DNA levels were not significantly reduced in root tissue and were higher in stem base than in any other tissues. Control, S06-, and S05-enriched soil plants had low F. culmorum DNA quantities in roots and stem bases. Streptomyces populations were present in the rhizosphere of plants in all treatments. Enrichment of potting soil with isolates S05 and S06 significantly increased Streptomyces densities, with the highest densities observed in the isolate S06-enriched treatment. Notably, dual inoculation of Streptomyces isolates and F. culmorum significantly increased the densities of Streptomyces in the rhizosphere compared with inoculation with Streptomyces alone, with increases of sixfold and fourfold recorded for S05 and S06, respectively (Table 3, Fig. 3). Streptomyces densities in soil and $F$. culmorum DNA levels in plant tissue (fungal colonization) were not correlated.

TABLE 2

Inhibitory potential of three Fusarium culmorum and two F. graminearum isolates against 17 inhibitory and non-inhibitory Streptomyces isolates, coefficient of variation (CV) of mean inhibition zones of individual Fusarium against Streptomyces isolates (columns), and CV of mean inhibition of Fusarium spp. against individual Streptomyces isolates (rows) ${ }^{2}$

\begin{tabular}{|c|c|c|c|c|c|c|c|c|}
\hline \multirow{2}{*}{ Streptomyces isolates } & \multirow{2}{*}{$\begin{array}{l}\text { Inhibitory to } \\
\text { Fusarium } \\
\text { (yes/no) }\end{array}$} & \multicolumn{6}{|c|}{$\begin{array}{l}\text { Inhibitory potential of Fusarium spp. against Streptomyces spp. isolates (mean inhibition } \\
\text { zone [mm] } \pm \text { standard deviation) }\end{array}$} & \multirow{2}{*}{ CV $(\%)$} \\
\hline & & \multicolumn{3}{|c|}{ F. culmorum isolate } & \multicolumn{2}{|c|}{$F$. graminearum isolate } & Mean & \\
\hline 1231.5 & Yes & $3.0 \pm 1.2$ & $2.1 \pm 0.5$ & $1.7 \pm 0.3$ & $2.1 \pm 0.8$ & $2.2 \pm 0.1$ & $2.2 \pm 0.7$ cdefg & 32.9 \\
\hline 2233.5 & Yes & $2.3 \pm 0.5$ & $2.1 \pm 0.3$ & $4.2 \pm 0.1$ & $2.1 \pm 1.0$ & $3.1 \pm 0.3$ & $2.8 \pm 0.9 \mathrm{cde}$ & 33.8 \\
\hline 3212.5 & Yes & $1.0 \pm 0.0$ & $1.0 \pm 0.0$ & $0.0 \pm 0.0$ & $0.0 \pm 0.0$ & $1.0 \pm 0.0$ & $0.6 \pm 0.5 \mathrm{fgh}$ & 84.5 \\
\hline GS $4-17$ & Yes & $1.0 \pm 0.0$ & $0.5 \pm 0.0$ & $0.0 \pm 0.0$ & $1.0 \pm 0.0$ & $1.5 \pm 0.2$ & $0.8 \pm 0.5$ efgh & 66.3 \\
\hline GS 4-24 & No & $2.4 \pm 0.4$ & $1.8 \pm 0.3$ & $0.0 \pm 0.0$ & $2.1 \pm 0.0$ & $2.6 \pm 0.2$ & $1.8 \pm 1.0$ defgh & 55.0 \\
\hline GS 8-22 & Yes & $1.4 \pm 0.3$ & $2.5 \pm 0.2$ & $2.4 \pm 0.2$ & $3.4 \pm 0.5$ & $3.2 \pm 0.1$ & $2.6 \pm 0.8$ cdef & 30.3 \\
\hline S05 & Yes & $3.6 \pm 0.5$ & $3.8 \pm 0.1$ & $2.0 \pm 0.1$ & $4.9 \pm 0.2$ & $4.2 \pm 1.0$ & $3.7 \pm 1.1 \mathrm{~cd}$ & 28.9 \\
\hline S06 & No & $0.0 \pm 0.0$ & $0.0 \pm 0.0$ & $0.0 \pm 0.0$ & $1.0 \pm 0.3$ & $1.4 \pm 0.2$ & $0.5 \pm 0.6 \mathrm{gh}$ & 131.0 \\
\hline S07 & No & $2.7 \pm 0.6$ & $0.9 \pm 0.4$ & $8.9 \pm 1.1$ & $1.2 \pm 0.3$ & $1.8 \pm 0.1$ & $3.1 \pm 3.1 \mathrm{~cd}$ & 101.4 \\
\hline S08 & No & $4.2 \pm 0.2$ & $4.4 \pm 0.3$ & $1.1 \pm 0.1$ & $5.0 \pm 0.3$ & $5.9 \pm 0.1$ & $4.1 \pm 1.7 c$ & 40.8 \\
\hline S09 & No & $0.0 \pm 0.0$ & $0.0 \pm 0.0$ & $0.0 \pm 0.0$ & $0.0 \pm 0.0$ & $0.0 \pm 0.0$ & $0.0 \pm 0.0 \mathrm{~h}$ & 0.0 \\
\hline \multirow[t]{2}{*}{$\mathrm{S} 10$} & No & $6.2 \pm 0.4$ & $8.1 \pm 0.6$ & $2.6 \pm 0.2$ & $7.9 \pm 0.9$ & $10.1 \pm 0.4$ & $7.0 \pm 2.7 b$ & 37.9 \\
\hline & Mean & $2.6 \pm 2.3 \mathrm{a}$ & $2.6 \pm 2.6 \mathrm{a}$ & $2.4 \pm 2.6 \mathrm{a}$ & $3.3 \pm 3.9 \mathrm{a}$ & $3.5 \pm 3.5 \mathrm{a}$ & & \\
\hline CV (\%) & & 82.4 & 99.2 & 110.0 & 117.5 & 100.6 & & \\
\hline
\end{tabular}

$\mathrm{z}$ Inhibition zones were assessed in vitro in a plate on oatmeal agar medium after 3 to 4 days of incubation. Mean inhibition zones in columns and rows followed by the same letter are not significantly different according to Tukey test $(P \leq 0.05)$ performed within a generalized linear model, $n=3$. 


\section{DISCUSSION}

Biocontrol of Fusarium crown and root rot by Streptomyces isolates. This work illustrates the potential but also challenges using Streptomyces isolates for biological control of FCR of wheat. Specifically, Streptomyces isolates showed inhibitory potential toward Fusarium spp. isolates in vitro and one isolate (S05) tested reduced wheat stem base and root colonization with $F$. culmorum by $75 \%$ under controlled conditions, compared with inoculation with F. culmorum alone. Conversely, a Streptomyces isolate classified as

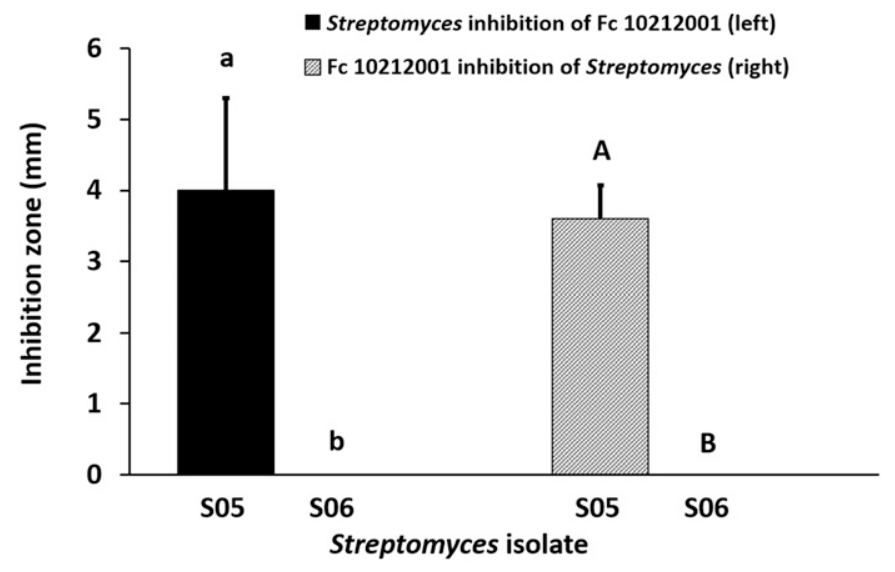

Fig. 1. Mean inhibition zones (bars, $\mathrm{mm}$ ) \pm standard deviation (error bars) of Streptomyces isolates against the Fusarium culmorum (Fc) isolate 10212001 (left) and Fc 10212001 against Streptomyces (right). Inhibition zones were assessed in an in vitro plate assay. Different lowercase and uppercase letters indicate significant differences in inhibition zones between Streptomyces isolates against 10212001 and 10212001 against Streptomyces isolates, respectively, according to Tukey test $(P \leq 0.05)$ performed within a generalized linear model, $n=3$.

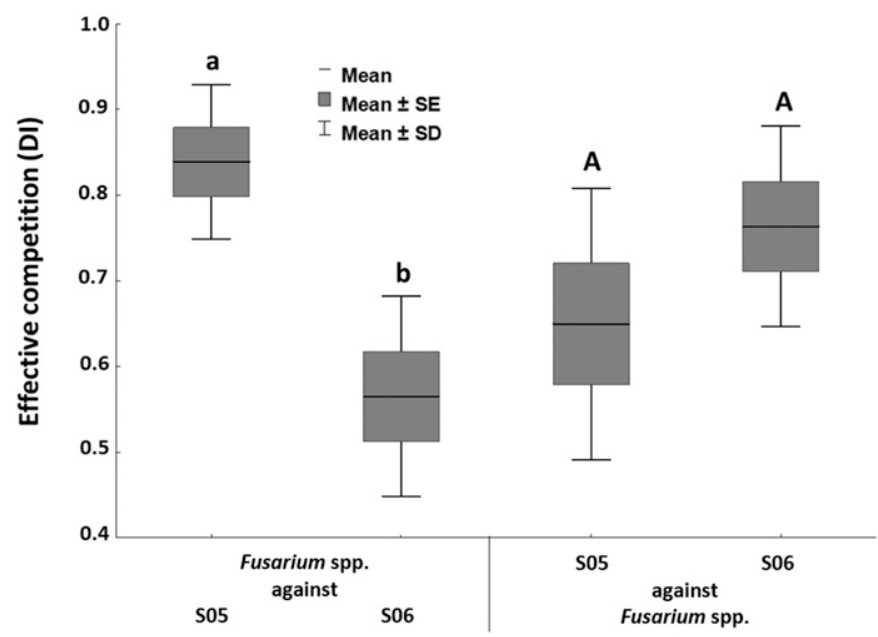

Fig. 2. Mean effective competition (EC) of Fusarium spp. isolates in relation to inhibitory Streptomyces isolate S05 and non-inhibitory Streptomyces isolate $\mathrm{S} 06$ and vice versa. In order to interrogate resource competition between isolates, EC was evaluated in a pairwise, asymmetric manner that would account for the impact one isolate would have on another and vice versa. For the calculation of $E C$, see methods. The genus had no significant effect on EC (one-way analysis of variance $[P=0.951]$ within a generalized linear model [GLM]). Different lowercase and capital letters indicate significant differences in EC between Fusarium against Streptomyces isolates and Streptomyces against Fusarium spp. isolates, respectively, according to Tukey test performed within a GLM, $n=5$. non-inhibitory to Fusarium spp. isolates in vitro (S06) showed no effect on $F$. culmorum colonization of roots and stem bases of wheat. The in vitro results were mirrored by the greenhouse experiments conducted in this study. It may be that inhibition of F. culmorum by Streptomyces occurs by similar mechanisms in vitro and in soil in planta, suggesting that the in vitro inhibition assay may serve as a useful diagnostic tool for identifying candidate biocontrol strains that may be effective in reducing FCR of wheat.

Antagonistic activity of Streptomyces against pathogens may be achieved through different mechanisms, including antibiosis, nutrient competition, production of degradative enzymes, induced resistance, nitrous oxide production, and quorum quenching (Cohen and Mazzola 2006; Cohen et al. 2005; Mahadevan and Crawford 1997; Mahmoudi et al. 2011). In our competitive plate assays, we tested antagonism by antibiosis, whereby secondary metabolites diffuse through the agar medium. Differences in densities of Streptomyces in treatments with and without co-inoculation of F. culmorum and Streptomyces isolates suggest that competition was of minor importance for antagonism. Both tested Streptomyces isolates, inhibitory and non-inhibitory, co-inoculated with F. culmorum significantly increased Streptomyces densities in the rhizosphere, but only S05 reduced plant colonization. In contrast, the non-inhibitory Streptomyces isolate S06 achieved the highest densities in the rhizosphere when co-inoculated with $F$. culmorum, and did not inhibit Fusarium colonization. There are several possible explanations for the observed effect of $F$. culmorum on Streptomyces densities. Two likely explanations are that F. culmorum changed the habitat (e.g., F. culmorum activity may have made nutrients accessible for Streptomyces) or stimulated Streptomyces proliferation through the production of secondary metabolites. Noteworthy, the well-known and -investigated trichothecene mycotoxins produced by $F$. culmorum during wheat root colonization do not inhibit Streptomyces isolates (unpublished data). However, subinhibitory concentrations of antimicrobial metabolites have been reported to act as signaling molecules by altering nutrient utilization and gene expression (Fajardo and Martínez 2008; Vaz Jauri et al. 2013), they may be prime candidates for triggering sporulation or altering the growth dynamics of

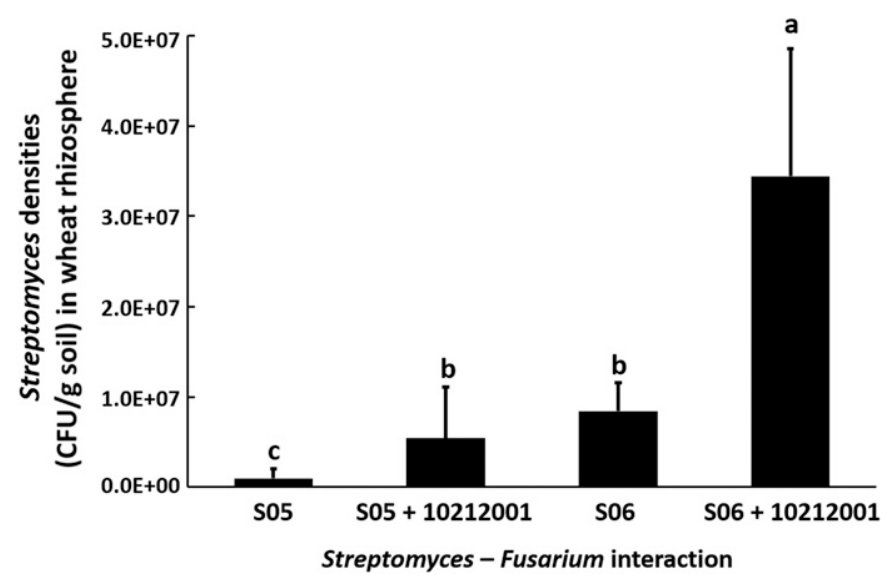

Fig. 3. Mean Streptomyces density (CFU per g of soil) in wheat rhizosphere soil among plants inoculated with the Fusarium culmorum isolate 10212001 and/or Streptomyces isolates S05 and S06 4 weeks after incubation. Densities reflect numbers after subtracting background Streptomyces densities, measured in the treatment inoculated with 10212001 alone. Different letters indicate significant differences between treatment means according to Tukey's honestly significant difference test for unequal means $(P \leq 0.05)$, performed within a generalized linear model, $n=12$ and $n=8$ for $10212001+$ S06, respectively. 
Streptomyces. It is likely that secondary metabolites of Fusarium spp. might act as signaling molecules, and thus enhance the antagonistic activity of Streptomyces populations, which we did not test in our study. This should be addressed in future research to explain the highly complex interactions between Fusarium spp. and Streptomyces isolates.

To our knowledge, this is the first study to show that a Streptomyces isolate, identified as inhibitory in vitro, can protect wheat roots and stem bases from $F$. culmorum colonization. However, coinoculation of this strain (S05) with $F$. culmorum did not reduce FCR disease and/or did not influence plant biomass of wheat. The results of this study differ from previous research showing that seed-coating with Streptomyces can significantly reduce seedling blight, disease incidence and severity of seedborne FCR of wheat (Berg et al. 2001; Roberti et al. 2000). However, in the latter and in this study, the practical potential of Streptomyces for the control of FCR in the field remains unknown. We believe that coating of wheat seeds with antagonistic Streptomyces isolates is unlikely to be efficient for biological control of FCR in the field. Chlamydospores and Fusarium-colonized plant debris in the first $10 \mathrm{~cm}$ of soil are considered the primary source of inoculum for FCR (Cook 1980), which initiate the infection of the coleoptile and the stem base of wheat. Therefore, enriching the soil with antagonists seems to be more promising to control FCR of wheat. However, a major challenge for large-scale biological control of FCR in the field will be the establishment of effective methods to enrich the soil with antagonistic microbial populations, including Streptomyces. Rice grains (Soares et al. 2007) or wheat bran (ElTarabily et al. 2000) may serve as suitable substrates for mass production of antagonist inoculum, but have not yet been evaluated for FCR suppression of wheat. Further studies are needed to investigate whether inhibitory Streptomyces populations can be established in the field to prevent wheat root and stem base colonization by F. culmorum and yield losses caused by FCR of wheat.

Streptomyces-Fusarium spp. interactions are highly isolatespecific. The two Streptomyces isolates used in growth chamber experiments not only differed in their inhibitory activity against Fusarium spp. isolates but also in their resource utilization and resource use overlap with Fusarium spp. isolates, which was evaluated by comparison of individual resource use phenotypes obtained after incubation in monoculture on biology plates. The assumption that resource similarity found in in vitro assays using Biolog plates is related to resource competition in soil was based on the findings by Kinkel et al. (2014) showing that resource competition data obtain in Biolog assays shed light on species interaction dynamics in soil. Among the five Fusarium spp. isolates, average Streptomyces niche overlap with Fusarium was higher for isolate S05 than for isolate S06. High effective competition (niche overlap) between coevolved microbes is related to high inhibitory potential among sympatric Streptomyces and Fusarium populations (Essarioui et al. 2017; Kinkel et al. 2014). In keeping with this finding, Streptomyces isolate $\mathrm{S} 05$ and F. culmorum isolate 10212001 showed both high niche overlap and strong reciprocal inhibition, which might indicate coevolution of S05 and F. culmorum. As stated earlier, direct competition might not have been responsible for antagonism, but it is likely that high niche overlap induced the production of antimicrobial compounds against Fusarium in S05. Conversely, Streptomyces isolate S06 and F. culmorum isolate 10212001 failed to demonstrate antagonism for each other and competed less for nutrients. This might explain why isolate S06 was able to proliferate strongly and where the stem bases in treatments enriched by this isolates showed elevated colonization by $F$. culmorum in terms of fungal DNA during co-inoculation. The Streptomyces isolates were obtained from two different wheat fields in Minnesota, which also varied in the soil type and characteristics and cropping history, which have been shown to influence the frequency of antagonistic Streptomyces phenotypes in soil (Bakker et al. 2010; Bailey and Kassen 2012; Essarioui et al. 2017; Kinkel et al. 2011; Otto-Hanson et al. 2013; Schlatter et al. 2009). In our study, we found highly specific inhibitory interactions between Fusarium spp. and Streptomyces isolates that were only in few cases related to niche overlap between isolates, and were not consistently reciprocal. The lack of recent coevolutionary interactions between Fusarium spp. and Streptomyces isolates investigated here may account for the absence of specific relationships between inhibitory and resource use phenotypes among Fusarium-Streptomyces pairs.

Interestingly, each Streptomyces isolate demonstrated fairly uniform resistance to inhibition by different Fusarium spp. isolates, whereas each Fusarium spp. isolate exhibited widely varying resistances to Streptomyces antagonism. It may be that inhibitory

TABLE 3

Survival rate of seedlings, mean disease symptoms on roots, mean disease ratings on stem bases, fresh weights (FW) of roots and above-ground plant material (referred as stem base), Fusarium culmorum DNA content, and Streptomyces density in rhizosphere soil 4 weeks after inoculation of wheat seedlings with F. culmorum (isolate 10212001), and/or amendment with an inhibitory (S05) or non-inhibitory (S06) Streptomyces isolate

\begin{tabular}{|c|c|c|c|c|c|c|c|c|}
\hline \multirow[b]{2}{*}{$\begin{array}{l}\text { Inoculation/amendment } \\
\text { treatment }\end{array}$} & \multirow[b]{2}{*}{$\begin{array}{l}\text { Survival } \\
\text { rate (\%) }\end{array}$} & \multicolumn{3}{|c|}{ Roots } & \multicolumn{3}{|c|}{ Stem base } & \multirow[b]{2}{*}{$\begin{array}{c}\text { Streptomyces } \\
\text { density (CFU per g of soil) }\end{array}$} \\
\hline & & $\begin{array}{l}\text { Disease } \\
\text { rating (\%) }\end{array}$ & $\mathrm{FW}(\mathrm{g})$ & $\begin{array}{l}\text { F. culmorum } \\
\text { DNA content } \\
\text { (pg per mg FW) }\end{array}$ & $\begin{array}{l}\text { Disease } \\
\text { rating (0 to } 3 \\
\text { scale) }\end{array}$ & FW (g) & $\begin{array}{l}\text { F. culmorum } \\
\text { DNA content } \\
\text { (pg per mg FW) }\end{array}$ & \\
\hline F. culmorum & 85.7 & $3.8 \mathrm{a}$ & $0.50 \mathrm{c}$ & $49.40 \mathrm{a}$ & $0.29 a b$ & $1.22 \mathrm{~b}$ & $133.34 \mathrm{a}$ & $4.10 E+04 d$ \\
\hline F. culmorum + S05 & 76.7 & $1.8 \mathrm{ab}$ & $0.55 \mathrm{bc}$ & $11.15 b$ & $0.46 a b$ & $1.09 \mathrm{~b}$ & $31.86 \mathrm{bc}$ & $5.66 \mathrm{E}+06 \mathrm{~b}$ \\
\hline F. culmorum + S06 & 63.3 & $4.0 \mathrm{a}$ & $0.57 \mathrm{abc}$ & $31.23 \mathrm{ab}$ & $0.79 a$ & $1.19 \mathrm{~b}$ & $416.46 \mathrm{ab}$ & $1.41 \mathrm{E}+07 \mathrm{a}$ \\
\hline S06 & 100 & $0.0 \mathrm{~b}$ & $0.76 \mathrm{a}$ & $4.52 \mathrm{c}$ & $0.13 a b$ & $2.15 \mathrm{a}$ & $38.66 \mathrm{bc}$ & $3.11 E+06 b$ \\
\hline Control & 100 & $1.6 \mathrm{ab}$ & $0.66 a b c$ & $1.82 \mathrm{~d}$ & $0.00 \mathrm{~b}$ & $2.19 \mathrm{a}$ & $13.70 \mathrm{c}$ & $1.35 E+05 d$ \\
\hline
\end{tabular}

Different letters within a column indicate significant differences according to Kruskal-Wallis test (disease ratings for stem bases considered separately) and Tukey test $(P \leq 0.05)$. Data for disease ratings in roots, DNA, and Streptomyces densities were transformed with the formula $\log (x+1)$ prior to analysis of variance, $n=12$ and $n=8$ for $10212001+$ S06, respectively. 
activity of $F$. culmorum and $F$. graminearum is based on only a few metabolites that are differentially bioactive toward different Streptomyces isolates. High diversity in resistance among Streptomyces to multiple antibiotic compounds has been shown in several studies (Davelos et al. 2004; Fujisawa and Weisblum 1981; Phillips et al. 1994). However, knowledge on the mechanisms of Fusarium inhibition of other microbes, especially soil bacteria, is scarce. It has been shown that fusaric acid, which can be produced by many Fusarium species (Bacon et al. 1996; Brown et al. 2015), suppresses the production of antifungal metabolites by the ubiquitous soil bacterium Pseudomonas (Duffy and Défago 1997; van Rij et al. 2005). Fusaric acid is predominantly produced by Fusarium species in the section Liseola, including $F$. moniliforme, $F$. solani, and $F$. oxysporum (Bacon et al. 1996), and not by $F$. culmorum and $F$. graminearum (Brown et al. 2015; Hansen et al. 2015; Vanheule et al. 2016). The latter two Fusarium species are not only the predominant causal agents of FCR of wheat, but are also considered to play key roles in nutrient cycling and in shaping soil microbial communities (King et al. 2011; LeBlanc et al. 2017; Li et al. 2008). Presumably, these impacts are based in part on their inhibitory activities against indigenous soil microbes. Further studies are needed identifying the bioactive metabolites produced by $F$. culmorum and $F$. graminearum during their interactions with soil bacteria. In conclusion, Streptomyces isolates can effectively reduce the colonization of wheat roots and stem bases by the fungal pathogen $F$. culmorum, which may be the starting point of identifying practical biocontrol for FCR in the field. Our study supports a previous finding (Essarioui et al. 2017) that Fusarium can also effectively inhibit Streptomyces, though it appears that this relationship is not consistently reciprocal. A better understanding of Fusarium-Streptomyces interactions in soil mediated by both antagonism and effective competition are needed.

\section{ACKNOWLEDGMENTS}

We thank A. Essarioui and N. LeBlanc for critical discussions on methodology and data analyses of resource use characterization.

\section{LITERATURE CITED}

Bacon, C. W., Porter, J. K., Norred, W. P., and Leslie, J. F. 1996. Production of fusaric acid by Fusarium species. Appl. Environ. Microbiol. 62:4039-4043.

Bailey, S. F., and Kassen, R. 2012. Spatial structure of ecological opportunity drives adaptation in bacterium. Am. Nat. 180:270-283.

Bakker, M. G., Glover, J. D., Mai, J. G., and Kinkel, L. L. 2010. Plant community effects on the diversity an pathogen suppressive activity of soil streptomycetes. Appl. Soil Ecol. 46:35-42.

Beccari, G., Covarelli, L., and Nicholson, P. 2011. Infection processes and soft wheat response to root rot and crown rot caused by Fusarium culmorum. Plant Pathol. 60:671-684.

Becker, D. M., and Kinkel, L. L. 1999. Strategies for quantitative isolation of Streptomyces from soil for studies of pathogen ecology and disease biocontrol. Pages 349-362 in: Recent Research Developments in Microbiology, Research Signpost, Trivandrum, India.

Berg, G., Marten, P., Minkwitz, A., and Brückner, S. 2001. Efficient biological control of fungal plant diseases by Streptomyces sp. DSMZ 12424. JPDP 108:1-10.

Brown, D. W., Lee, S. H., Kim, L. H., Ryu, J. G., Lee, S., and Seo, Y. 2015. Identification of a 12-gene fusaric acid biosynthetic gene cluster in Fusarium species through comparative and functional genomics. Mol. Plant-Microbe Interact. 28:319-332.

Burgess, L. W., Backhouse, D., Summerell, B. A., Pattison, A. B., Klein, T. A., Esdaile, R. J., and Ticehurst, G. 1993. Long-term effects of stubble management on the incidence of infection of wheat by Fusarium graminearum Schw. Group 1. Aust. J. Exp. Agric. 33:451-456.

Challis, G. L., and Hopwood, D. A. 2003. Synergy and contingency as driving forces for the evolution of multiple secondary metabolite production by Streptomyces species. Proc. Natl. Acad. Sci. 100(suppl. 2):14555-14561.
Chekali, S., Gargouri, S., Paulitz, T., Nicol, J. M., Rezgui, M., and Nasraoui, B. 2011. Effects of Fusarium culmorum and water stress on durum wheat in Tunisia. Crop Prot. 30:718-725.

Clement, J., and Parry, D. 1998. Stem-base disease and fungal colonisation of winter wheat grown in compost inoculated with Fusarium culmorum, F. graminearum and Microdochium nivale. Eur. J. Plant Pathol. 104: 323-330.

Cohen, M. F., and Mazzola, M. 2006. Resident bacteria, nitric oxide emission and particle size modulate the effect of Brassica napus seed meal on disease incited by Rhizoctonia solani and Pythium spp. Plant Soil 286:75-86.

Cohen, M. F., Yamasaki, H., and Mazzola, M. 2005. Brassica napus seed meal soil amendment modifies microbial community structure, nitric oxide production and incidence of Rhizoctonia root rot. Soil Biol. Biochem. 37: 1215-1227.

Cook, R. J. 1980. Fusarium foot rot of wheat and its control in the Pacific Northwest. Plant Dis. 64:1061-1066.

Cook, R. J. 1981. Fusarium diseases of wheat and other small grains in North America. Pages 40-52 in: Fusarium: Diseases, Biology, and Taxonomy. P. E. Nelson, T. A. Toussoun, and R. J. Cook, eds. Pennsylvania State University Press, University Park.

Davelos, A. L., Kinkel, L. L., and Samac, D. A. 2004. Spatial variation in frequency and intensity of antibiotic interactions among streptomycetes from Prairie Soil. Appl. Environ. Microbiol. 70:1051-1058.

Dill-Macky, R. 2003. Inoculation methods and evaluation of Fusarium head blight resistance in wheat. Pages 84-210 in: Fusarium Head Blight of Wheat and Barley.K. J. Leonard and W. R. Bushnell, eds. American Phytopathological Society, St. Paul, MN.

Duffy, B. K., and Défago, G. 1997. Zinc improves biocontrol of Fusarium crown and root rot of tomato by Pseudomonas fluorescens and represses the production of pathogen metabolites inhibitory to bacterial antibiotic biosynthesis. Phytopathology 87:1250-1257.

Duthie, J., and Hall, R. 1987. Transmission of Fusarium graminearum from seed to stems of winter wheat. Plant Pathol. 36:33-37.

El-Tarabily, K. A., Soliman, M. H., Nassar, A. H., Al-Hassani, H. A., Sivasithamparam, K., and McKenna, F. 2000. Biological control of Sclerotinia minor using a chitinolytic bacterium and actinomycetes. Plant Pathol. 49:573-583.

Essarioui, A., LeBlanc, N., Kistler, H. C., and Kinkel, L. L. 2017. Plant community richness mediates inhibitory interactions and resource competition between Streptomyces and Fusarium populations in the rhizosphere. Microbiol. Ecol. 74:157-167.

Fajardo, A., and Martínez, J. L. 2008. Antibiotics as signals that trigger specific bacterial responses. Curr. Opin. Microbiol. 11:161-167.

Fouly, H., and Pedersen, W. 1996. What root rotting fungi in the "Old" and "New" agricultural lands of Egypt. Plant Dis. 80:1298-1300.

Fujisawa, Y., and Weisblum, B. 1981. A family of r-determinants in Streptomyces spp. that specifies inducible resistance to macrolide, lincosamide, and streptogramin type B antibiotics. J. Bacteriol. 146:621-631.

Hansen, F. T., Gardiner, D. M., Lysøe, E., Fuertes, P. R., Tudzynski, B., and Wiemann, P. 2015. An update to polyketide synthase and non-ribosomal synthetase genes and nomenclature in Fusarium. Fungal Genet. Biol. 75: 20-29.

King, B. C., Waxman, K. D., Nenni, N. V., Walker, L. P., Bergstrom, G. C., and Gibson, D. M. 2011. Arsenal of plant cell wall degrading enzymes reflects host preference among plant pathogenic fungi. Biotechnol. Biofuels 4:4.

Kinkel, L. L., Bakker, M. G., and Schlatter, D. C. 2011. A coevolutionary framework for managing disease-suppressive soils. Annu. Rev. Phytopathol. 49:47-67.

Kinkel, L. L., Schlatter, D. C., Xiao, K., and Baines, A. D. 2014. Sympatric inhibition and niche differentiation suggest alternative coevolutionary trajectories among Streptomycetes. ISME J. 8:249-256.

LeBlanc, N., Essariouri, A., Kinkel, L. L., and Kistler, H. C. 2017. Phylogeny, plant species, and plant diversity influence carbon use phenotypes among Fusarium populations in the rhizosphere microbiome. Phytobiom. 1: 150-157.

Li, L., Li, X.-Z., Tang, W.-Z., Zhao, J., and Qu, Y.-B. 2008. Screening of a fungus capable of powerful and selective delignification on wheat straw. Lett. Appl. Microbiol. 47:415-420.

Lorang, J. M., Liu, D., Anderson, N. A., and Schottel, J. L. 1995. Identification of potato scab inducing and suppressive species of Streptomyces. Phytopathology 85:261-268.

Mahadevan, B., and Crawford, D. L. 1997. Properties of the chitinase of the antifungal biocontrol agent Streptomyces lydicus WYEC108. Enzyme Microb. Technol. 20:489-493. 
Mahmoudi, E., Tabatabaei, B. E. S., and Venturi, V. 2011. Virulence attenuation of Pectobacterium carotovorum using N-Acyl-homoserine lactone degrading bacteria isolated from potato rhizosphere. Plant Pathol. J. 27:242-248.

Moya-Elizondo, E. A. 2013. Fusarium crown rot disease: Biology, interactions, management and function as a possible sensor of global climate change. Cienc. Investig. Agrar. 40:235-252.

Otto-Hanson, L. K., Grabau, Z., Rosen, C., Salomon, C. E., and Kinkel, L. L. 2013. Pathogen variation and urea influence selection and success of Streptomyces mixtures in biocontrol. Phytopathology 103:34-42.

Paulitz, T. C., Smiley, R. W., and Cook, R. J. 2002. Insights into the prevalence and management of soilborne cereal pathogens under direct seeding in the Pacific Northwest, U.S.A. Can. J. Plant Pathol. 24:416-428.

Phillips, L., Wellington, E. M. H., and Rees, S. B. 1994. The distribution of antibiotic resistance patterns within streptomycetes and their use in secondary metabolite screening. J. Ind. Microbiol. 13:53-62.

Poole, G. J., Smiley, R. W., Walker, C., Huggins, D., Rupp, R., and Abatzoglou, J. 2013. Effect of climate on the distribution of Fusarium spp. causing crown rot of wheat in the Pacific Northwest of the United States. Phytopathology 103:1130-1140.

Roberti, R., Flori, P., Pisi, A., Brunelli, A., and Cesari, A. 2000. Evaluation of biological seed treatment of wheat for the control of seed-borne Fusarium culmorum. JPDP 107:484-493.

Samac, D. A., and Kinkel, L. L. 2001. Suppression of the root-lesion nematode (Pratylenchus penetrans) in alfalfa (Medicago sativa) by Streptomyces spp. Plant Soil 235:35-44.

Scherm, B., Balmas, V., Spanu, F., Pani, G., Delogu, G., and Pasquali, M. 2013. Fusarium culmorum: Causal agent of foot and root rot and head blight on wheat. Mol. Plant Pathol. 14:323-341.

Schlatter, D., Fubuh, A., Xiao, K., Hernandez, D., Hobbie, S., and Kinkel, L. 2009. Resource amendments influence density and competitive phenotypes of Streptomyces in soil. Microbiol. Ecol. 57:413-420.

Smiley, R., and Patterson, L.-M. 1996. Pathogenic fungi associated with Fusarium foot rot of winter wheat in the semiarid Pacific Northwest. Plant Dis. 80:944-949.
Soares, A. C. F., Sousa, C. D. S., Garrido, M. D. S., and Perez, J. O. 2007. Production of streptomycete inoculum in sterilized rice. Sci. Agric. 64: 641-644.

van Rij, E. T., Girard, G., Lugtenberg, B. J. J., and Bloemberg, G. V. 2005. Influence of fusaric acid on phenazine-1-carboxamide synthesis and gene expression of Pseudomonas chlororaphis strain PCL1391. Microbiology $151: 2805-2814$

Vanheule, A., Audenaert, K., Warris, S., van de Geest, H., Schijlen, E., and Höfte, M. 2016. Living apart together: Crosstalk between the core and supernumerary genomes in a fungal plant pathogen. BMC Genomics 17:670.

Vaz Jauri, P., Bakker, M. G., Salomon, C. E., and Kinkel, L. L. 2013. Subinhibitory antibiotic concentrations mediate nutrient use and competition among soil streptomyces. PLoS One 8:e81064.

Watve, M. G., Tickoo, R., Jog, M. M., and Bhole, B. D. 2001. How many antibiotics are produced by the genus Streptomyces? Arch. Microbiol. 176: 386-390.

Wiggins, B. E., and Kinkel, L. L. 2005a. Green manures and crop sequences influence alfalfa root rot and pathogen inhibitory activity among soil-borne streptomycetes. Plant Soil 268:271-283.

Wiggins, B. E., and Kinkel, L. L. 2005b. Green manures and crop sequences influence potato diseases and pathogen inhibitory activity of indigenous streptomycetes. Phytopathology 95:178-185.

Wildermuth, G., Thomas, G., Radford, B., McNamara, R., and Kelly, A. 1997. Crown rot and common root rot in wheat grown under different tillage and stubble treatments in southern Queensland, Australia. Soil Tillage Res. 44: 211-224.

Winter, M., Koopmann, B., Doell, K., Karlovsky, P., and von Tiedemann, A. 2013. Mechanisms regulating grain contamination with trichothecenes translocated from the stem base of wheat (Triticum aestivum L.) infected with Fusarium culmorum. Phytopathology 103:682-689.

Winter, M., Samuels, P. L., Dong, Y., and Dill-Macky, R. 2018. Trichothecene production is detrimental to early root colonisation by Fusarium culmorum and F. graminearum in Fusarium crown and root rot of wheat. Plant Pathol. 68:185-195. 